\title{
Modification in microbiota and evaluation by cone beam computed tomography during orthodontic treatment
}

\author{
Bottacin FS, ' Stuani MB, ${ }^{2}$ Taba M Jr ${ }^{3}$ \\ 'Department of Morphology, Physiology and Basic Pathology, FORP/USP, Brazil \\ ${ }^{2}$ Department of Children's Clinic, FORP/USP, Brazil \\ ${ }^{3}$ Department of Buco-Maxillofacial Surgery and Traumatology and Periodontics, FORP/USP, Brazil
}

Correspondence: Bottacin FS, Department of Morphology, Physiology and Basic Pathology, FORP/USP, Brazil, Email fabio.santos.b@hotmail.com

Received: July 07, 2018 | Published: July 17, 2018

Copyright@ 2018 Bottacin et al. This is an open access article distributed under the terms of the Creative Commons Attribution License, which permits unrestricted use, distribution, and reproduction in any medium, provided the original author and source are credited.

\begin{abstract}
This bibliographical review had as main objective to discuss the literature regarding the alterations in the gingival microbiota and on the use of the conical beam computed tomography. From the expository analysis, it will be possible to perform clinical research and increase knowledge about orthodontic therapy. This work was carried out through a Pubmed database, of articles written on the subject in question, using as key words in the Portuguese and English languages: Orthodontics, Periodontics, Cone Beam Computed Tomography.
\end{abstract}

Keywords: orthodontics, periodontics, english languages, stomatognathic system, microbiota

\begin{abstract}
Abbreviations
2D, two-dimensional; 3D, three-dimensional; HOMIM, human oral microbe identification microarray; MPR, multiplanar reformatting

\section{Introduction}

Modern dentistry values the study of dental occlusion and its relationship with the functions of the stomatognathic system, aiming at achieving oral health, anatomical and functional harmony and stability of the occlusion. If there is harmony between form and function, the relationships will be stable and the treatment can be considered integral. ${ }^{1,2}$
\end{abstract}

Some points can be discussed in relation to Orthodontics vs Periodontics. A questionable point would be regarding the changes occurred in the microbiota due to the installation of orthodontic appliances. ${ }^{3-7}$ Although Thornberg et al. $^{8}$ stated that orthodontic treatment with fixed appliances did not increase the risk of elevation of periodontal pathogens, some authors still understand this procedure as a two-way pathway, which can sometimes be very significant in increasing periodontal health status and, in other situations, may lead to some periodontal complications..$^{9-12}$ It is important to note that some studies have stated that the gingival and periodontal changes that occur during orthodontic treatment are temporary and do not normally result in permanent periodontal loss., $3,7,14$ However, other authors have suggested increased loss of clinical insertion during orthodontic treatment. ${ }^{3,14-16}$

For more than half a century, lateral and frontal radiographs, as well as panoramic and periapical radiographs, have been standard as complementary examinations in several dental specialties. However, traditional cephalometric measurements are performed on twodimensional (2D) images of three-dimensional (3D) structures, not often reflecting reality. There may be projections and overlaps of bilateral structures, magnified in different ways, with consequent difficulty in marking cephalometric points. ${ }^{17}$

Recent advancements in dental technology technology allow the combination of cephalometric principles and tools with the advantages of CT scans. The accomplishment of the measurements in CT provides the real evaluation of the changes in growth and development, since they represent the reliable orofacial anatomy. ${ }^{18}$ The 3D cephalometry allows the visualization of the cephalometric points with precision and without distortions, giving an analysis of the actual changes that have occurred. ${ }^{17}$

\section{Discussion}

Periodontitis is a group of infections that affect the periodontium of protection and support of the teeth, causing a progressive loss of insertion, of bone tissue and, eventually, of the dental element. Regarding the microbiota associated with these infections, it is already well established in the literature that gingivitis is due to the undifferentiated accumulation of bacteria in the gingival margin, while periodontal diseases are associated with an increase in the levels and proportions of pathogenic species and the concomitant decrease of species compatible with the host. ${ }^{19}$ The specific infectious character of periodontitis was suggested in the $1970 \mathrm{~s}$ and $1980 \mathrm{~s}^{20-23}$ 
Immediately after the installation of the orthodontic appliances we can observe unfavorable changes in the subgingival microbiota leading to the development of gingivitis and possibly even periodontitis. ${ }^{7,12,24-27}$ These changes, in addition to being related to the deficiency in oral hygiene, ${ }^{25,26}$ are also directly related to the quantitative and qualitative changes of the microbiota located around orthodontic accessories, causing inflammation and tissue damage. In this sense, Perinetti et al. ${ }^{10}$ and Naranjo et al. ${ }^{25}$ asserted that the worsening of the periodontal conditions due to biofilm accumulation can be attributed to the difficulty of oral hygiene around the brackets, leading to an increase in gingival volume due to the inflammatory process. Considering the quantitative levels of subgingival pathogens it is possible to observe that some appear increased in the first six months after installation of the fixed apparatus; however, usually return to pretreatment levels after 12 months in young individuals. ${ }^{8,28}$

More recent studies have focused on the evaluation of the oral microbiota in individuals submitted to orthodontic tre8tment. Lo Bue et al. ${ }^{12}$ evaluated the changes in microbiota and the clinical inflammatory parameters of patients within 12 weeks of orthodontic therapy. Subgingival biofilms and tongue samples were collected at baseline, two, four and 12 weeks. It is important to note that patients were being motivated to control oral hygiene. Clinical results demonstrated that at 12 weeks the mean plaque index and gingival index was lower than at the baseline. Another important point of the study was the observation that $87.5 \%$ of the evaluated regions received 0 and 1 in the plaque index and only $12.5 \%$ received two and three in the same index, demonstrating that oral hygiene restricts the development of the bio film during orthodontic therapy. Therefore, due to the observation of the pathogenic behavior of anaerobic bacteria responsible for gingivitis and periodontitis, the authors emphasize the importance of monitoring these anaerobic bacteria during the installation of the fixed orthodontic appliance.

Torlakovic et al. ${ }^{29}$ measured the impact of fixed appliances on the supragingival microbiota. Four times (before installation of the device, four weeks, three months and five months) were used for biofilm collection, plaque index evaluation and gingival evaluation using photographs. In the evaluation of the biofilm samples, the test used was a variation of the PCR-the Human Oral Microbe Identification Microarray (HOMIM) - that detected a non-significant increase of the biofilm after the bonding of the brackets. On the other hand, gingivitis increased from $25 \%$ before onset to $74 \%$ at five months. They also emphasized the tendency of the microbiota to be associated with bacteria with the potential to develop periodontitis and caries disease, and that these changes were not severe enough. Therefore, the authors suggested that treatment with fixed appliances does not necessarily change the microbiota to a more permanent pathogenic composition.

The microbiological monitoring and clinical parameters of patients in orthodontic therapy was the subject of the research by Ghijselings et al. ${ }^{30}$ followed for two years after treatment. In the treatments, two groups with brackets and one with brackets and bands were used. Depth of probing, bleeding at probing, crevicular fluid collected at the baseline, removal of the appliance and two-year orthodontic treatment were assessed. They reported that the pathogenic potential of the biofilm increased from the baseline until the removal of the device, and the reduction during the period of removal of the device until the two years. No significant changes were observed in the proportion of colonies of aerobic and anaerobic species from supragingival biofilm samples between the baseline and the two-year period. However, when the subgingival samples were considered, the proportion of aerobic and anaerobic species presented different between the two times. They observed an increase in depth of probing and crevicular fluid between the baseline and removal of the device, and the reduction between removal of the appliance and two years. Only for bleeding at the banding group, no changes were observed between the two years posttreatment and the baseline. Thus, the authors suggested that fixed orthodontic therapy causes changes in clinical parameters and these changes are partially reversible, since they regress but even two years after treatment do not return to baseline values.

The accumulation of biofilm increases soon after the installation of fixed appliances and are still associated according to Ireland et al. ${ }^{31}$ demineralization of enamel and gingival inflammation. The authors evaluated biofilm samples of self-ligating brackets, bands (only in one hemiarco) and elastomeric ligatures of young patients, at regular intervals during treatment and one after removal of the fixed appliance. They observed changes within three months of starting treatment. The most significant differences occurred in the composition of the self -ligating biofilm with elastomeric ligation. Therefore, orthodontic therapy changes the composition of the biofilm, and such alteration may be more expressive with the association of bands. For YáñezVico et al..$^{32}$ the study of clinical and microbiological parameters in orthodontic patients is very important. They evaluated 112patients in two groups, with and without fixed appliance. In the group with fixed apparatus the samples were obtained in the baseline and 10days after the removal of the brackets; the other group without apparatus was considered control. Subgingival biofilm samples, plaque index and bleeding were used. They pointed to changes in bleeding at the probe and plaque index at baseline and 10days after removal, between baseline and control group data, and between the time 10days after removal and the data from the control group. There was a reduction in the prevalence of $T$. denticola between baseline and 10days after removal. In the same 10days after removal, there was a positive correlation between bleeding at the probe and the prevalence of $A$. actinomycetemcomitans and also between clinical parameters and the prevalence of $P$. intermedia. In the control group and within 10 days after removal another positive correlation was observed between the plaque index and T. forsythia. Therefore, local factors associated with fixed orthodontic therapy may alter the subgingival biofilm causing increased inflammation and bleeding.

In periodontal disease the onset and its development are directly related to the dynamic balance between the microbiota, the immunological and inflammatory responses of the host. Among the clinical alterations, the increase in gingival volume occurs between one and two months after the beginning of the installation of the fixed appliance and can be considered a routine alteration in orthodontic practice. With the presence of brackets the accumulation and colonization of periodontopathogenic bacteria is present. In response to aggression occurs the increase in gingival volume, which may further hamper oral hygiene procedures. As a consequence, there is also an increase in levels of gingival bleeding. Brachial design and material may also interfere with plaque build-up causing inflammation and directing increased pocket depth resulting in increased gingival volume. . $^{7,89,10,13,28,33-39}$

Another constant finding related to the inflammatory process is the increase of the probing depth. In adult patients the mean purse depth may increase slightly during orthodontic treatment. This change should not be considered statistically or clinically significant and 
could probably be a response due to increased supragingival biofilm accumulation and gingival inflammation during the 12 months of orthodontic therapy in the region of the cast fittings, $, 14,24,33,34,40-43$ and in the present study. ${ }^{25,40}$

The recommended treatment involves periodontal therapy, often with temporary removal of the device. Thus, the reduction of the levels of periodontopathogenic microorganisms occurs, for example, $P$. gingivalis, A. actinomycetemcomitans and T. Denticola.$^{38}$ The authors report the return of probing depth levels to the initial parameters after removal of the brackets, ${ }^{4,9,34}$ as a result of tissue repair and the elimination of the signs of inflammation. $7,13,16,26,42,44$

Cone-beam computed tomography (CBCT) began to be used in dentistry in the mid-1990s. ${ }^{45}$ They are radiographs that produce multiplanar reformatting (MPR), that is, it is a type of technique that allows the reconstruction of images in different planes from a block of previously acquired images, making possible the reconstruction of the images in the axial, coronal and sagittal. ${ }^{46}$ The CBCT have many indications in Dentistry, highlighting the specialties Implantodontia. ${ }^{6,47,48}$ Endodontics, ${ }^{49}$ Maxillofacial Surgery, ${ }^{50}$ Periodontics $^{51-55}$ and Orthodontics. ${ }^{56-61}$ They can also aid in the location of impacted teeth, root resorption, detection of dehiscences and fenestrations, evaluation of the temporomandibular joint, asymmetries, upper airways, craniofacial growth and development, skeletal maturation, volume and bone remodeling, $45,50,54,58,61-64$ surgical planning and also provide the measurements obtained by the digitalization of points in the three-dimensional coordinates (3D) among others. ${ }^{45,46,62,65}$

CBCTs can be considered a fundamental exam in many situations where high resolution images are required, providing an assessment of the height and volume of the alveolar bone, providing a more accurate diagnosis without distortion or enlargement errors, and an adequate treatment plan. ${ }^{45,55,56,63}$ In this way, CBCT are currently indicated for patients with periodontal problems to verify the periodontal ligament in the detection of bone defects, observing interdental and interradicular bone loss, gingival contour changes or both, determination of bone volume, changes in the apical region and bone quality. In the present study, the use of periodontal treatment in the treatment of periodontal disease was investigated in the first phase of the periodontal treatment and in the sequence integrating the specialties. ${ }^{49,52,57-59}$

It should be noted that radiographic CBCT should follow the protocol where the radiation dose should follow the principle "as low as possible" - as low as reasonably achievable-ALARA principle. ${ }^{45,50,52,59,60,63,65,66}$ The doses used are three to seven times more than panoramic radiographs and $40 \%$ less than conventional CT scans. ${ }^{67,68}$ When the CBCT and conventional dental radiographs are compared in relation to the radiation dose, it can be stated that they are similar to the periapical complete examination, the method of choice for adult patients at the beginning of periodontal therapy. ${ }^{45,57,62}$

The CBCT is recommended for diagnosis, planning, in specific cases and also for the individual judgment of the professional. ${ }^{45,49,57,59,60,65,66,69}$ In the planning, we emphasize the possibility of classification of this alveolar bone,${ }^{54}$ in order to verify the amount of bone tissue in the upper incisors region ${ }^{54}$ and still in the detection of dehiscences and fenestrations. ${ }^{61} \mathrm{~A}$ disadvantage is related to the presence of amalgam restorations, obturator material in the root canals, implants and especially in brackets, wires and metallic bands, all these materials can generate distortions with radiopaque zones in the TCFC (artifacts), preventing the visualization of the structures, hindering the identification mainly when it overlaps the cement-enamel junction. ${ }^{55,63}$

It is important to search for effective methods capable of detecting bone defects caused by periodontal disease with computerized tomography (CT).${ }^{51}$ In this sense, the CBCT is the most up-to-date and proven $3 \mathrm{D}$ evaluation method in research, uses reduced radiographic exposure indexes, presents data with acceptable accuracy regarding changes that occur in bone tissue during orthodontic movement in vivo, presents data from the entire craniofacial region and also the possibility of manipulation of specific software images, in a 1:1 ratio, with anatomical representation compatible with reality for evidence-based dentistry, aiding diagnosis, treatment plan and prognosis. ${ }^{45,57,58,59,60,63,70,71}$

The advent of cone beam computed tomography represents the development of a relatively small and low cost tomograph, especially suitable for the dentomaxillofacial region. The development of this new technology provided to the Dentistry the reproduction of the three-dimensional image of the maxillofacial mineralized tissues, with minimal distortion and dose of radiation significantly reduced in comparison to the traditional computed tomography (CT) ${ }^{56,72}$ The first literary reports on cone beam computed tomography for use in dentistry occurred very recently in the late nineties. The pioneering of this new technology lies with the Italians Mozzo et al., University of Verona, who in 1998 presented the preliminary results of a "new volumetric CT for dental imaging based on cone beam technique", named NewTom $-9000 .^{73}$ They reported high accuracy of the images as well as a dose of radiation equivalent to $1 / 6$ that of traditional CT.

The TC cone beam programs, also to traditional CT, allow the multiplanar reconstruction of the scanned volume, ie the visualization of axial, coronal, sagittal and parasagittal images, as well as 3D reconstruction. ${ }^{57}$ In addition, the program allows the generation of two-dimensional images, replicas of conventional radiographs used in dentistry, such as panoramic and cephaladiographies in lateral and frontal norm, a function called multiplanar volume reconstruction, which is another important advantage of CT cone beam. ${ }^{74}$ On all these images, the software still allows the accomplishment of linear and angular digital measurements as well as coloring anatomical structures of interest. The total volume of the scanned area has a cylindrical shape, of variable size according to the brand of the apparatus, and is composed unitarily by voxel. Each side of the voxel has a submillimetric dimension (less than $1 \mathrm{~mm}$, usually 0.119 to $0.4 \mathrm{~mm}$ ) and, therefore, the CT image presents good resolution. ${ }^{66}$

For this reason, studies in the area of validation of cone beam CT for qualitative and quantitative analyzes showed a high image accuracy, ${ }^{52,75-80}$ besides good sharpness. The CT image of the conical bundle distinguishes enamel, dentin, pulp cavity and alveolar cortical ${ }^{81}$ The artifacts produced by metal restorations are much less significant than in traditional $\mathrm{CT} .{ }^{82}$ The effective radiation dose of the face CTB scan with $0.4 \mathrm{~mm}$ voxel is equivalent to the sum of the effective radiation dose of a lateral teleradiography, a panoramic view and a complete set of periapical radiographs. ${ }^{67}$

Cone beam computed tomography images allow detailed evaluation of facial morphology and dental positioning, as well as visualization of the buccal and lingual bone plates that could not be differentiated into conventional dental radiographs due to the overlap of images. In this way, this method of diagnostic imaging presents important applications in Orthodontics, as explained below: 
a) Evaluation of the three-dimensional positioning of retained teeth, and its relationship with neighboring teeth and structures. ${ }^{83}$

b) Evaluation of the degree of root resorption of adjacent teeth to retained canines. ${ }^{84}$

c) In the present study, it is possible to observe the presence of vestibular and lingual bone plaques and their remodeling after tooth movement. ${ }^{85-90}$

d) In the present study, we evaluated the transverse dimensions of apical bases and upper airway dimensions. ${ }^{91,92}$

e) Evaluation of tooth movement for aresic bone region and slightly thickened alveolar ridge in the vestibulolingual direction. ${ }^{93}$

f) In the present study, it was possible to determine the presence of defective bone grafts in the region of the cleft lip and palate. ${ }^{94-96}$

g) Quantitative and qualitative analysis of the alveolar bone for placement of orthodontic anchoring mini-implants. ${ }^{97-100}$

h) Cephalometric overlays and evaluations. ${ }^{101-103}$

The cone beam CT device is very compact and resembles the panoramic radiography apparatus. It presents two main components, positioned at opposite ends of the patient's head: the x-ray source or tube that emits a cone-shaped beam and an X-ray detector. The tube-detector system performs only a 360-degree rotation around the patient's head, and with each degree of rotation (usually every 1 degree), the device acquires a base image of the patient's head, much like a teleradiography, under different angles or perspectives. ${ }^{57}$ At the end of the exam, this sequence of raw data is reconstructed to generate the 3D volumetric image by means of a specific software with a sophisticated algorithm program installed in a conventional computer coupled to the tomography. ${ }^{57}$ The time of examination can vary from 10 to 70 seconds (a complete revolution of the system), but the time of effective exposure to the X-rays is much smaller, ranging from 3 to 6 seconds. ${ }^{56}$

Dental movements that tend to decentralize the alveolar ridge teeth represent the most critical movements for the development of bone dehiscences ${ }^{88}$ The movement in the buccolingual direction presents a greater risk of transposing the limits of the alveolar ridge, resulting in reabsorption of the free bone plates. There is a clear correlation between buccolingual tooth movement and the development of bone dehiscences. Animal studies have shown that buccal-buccal tooth dislocation increases the distance between the cementumenamel junction and the buccal bone crest. ${ }^{104-107}$ Interestingly, studies conducted in human maxillary extracted at autopsy showed similar conclusions. ${ }^{108-110}$ The reductive changes in the thickness and level of the buccal bone plate signal the absence of equivalent compensatory bone apposition under the buccal periosteum when the teeth are moved in that direction. The development of bone dehiscences consequent to the sagittal movement of the incisors was also suggested by studies using conventional radiographs and laminographies ${ }^{111,112}$ and by clinical studies that verified the development of gingival recessions in natural or orthodontically entrance exam. ${ }^{113-116}$

Computed tomography extended the visualization of the repercussions of tooth movement on the vestibular and lingual alveolar bone. CT, it was observed that the expansion, protrusion and retraction with translation are among the movements with a higher risk of causing bone dehiscence ${ }^{88}$ The orthodontic retraction of the upper and lower incisors causes a reduction in the thickness of the lingual bone board in the middle and coronal thirds, as well as lingual bone dehiscences. ${ }^{89}$ The thickness of the buccal bone plate remains constant before the incisors are retracted, except for the region of the coronal third of the lower incisors, which may show a reduction. ${ }^{89}$ The pre-surgical decompensatory orthodontic treatment in vertical patients with a Class III skeletal pattern can determine extensive bone dehiscences in the mandibular symphysis region. ${ }^{117}$ Both the rapid maxillary expansion ${ }^{90,118}$ and the slow expansion ${ }^{88}$ in the permanent denture may cause vestibular bone dehiscences in the posterior teeth, especially in patients with initially thin bone.

The region of the first maxillary premolars is even more critical when compared to the region of the first molars, due to the anatomical characteristics of the maxilla. The first premolars are located in a gradually narrower area superiorly. In this region, in front of a body movement to vestibular, the root can transpose the alveolar bone much more easily. This evidence is important in guiding the orthodontist to take action to prevent future gingival recessions. The predisposing and triggering factors of gingival recessions should be prevented in cases submitted to expansion. Initially, gingival grafting should be recommended in areas with a small range of keratinized mucosa and guiding patient hygiene to avoid traumatic brushing and gingival inflammation. ${ }^{90}$

During the last decade, Orthodontics has increased its diagnostic potential and ability to delineate a more realistic prognosis with the introduction of cone beam CT. The morphology of the support periodonum, observed in computed tomography images, may alter usual orthodontic goals. In addition, the repercussions of tooth movement on the alveolar bone, evidenced by means of computed tomography, indicate the limits of Orthodontics, defining procedures that could and should not be implemented.

\section{Acknowledgements}

FAPESP - Grant number: 2015/20095-1.

\section{Conflict of interest}

The author declares no conflict of interest.

\section{References}

1. Dawson PE. Concept of integral dentistry. In: Dawson P.E. Evaluation, diagnosis and treatment of occlusal problems. 2nd ed. são Paulo: Artes Médicas; 1993. p.1-14.

2. Faltin Júnior K, Faltin RM, Faltin CO. Ortopedia facial e ortodontia preventiva na saúde bucal. In: Kriger L, editor. ABOPREV: Promoção de saúde bucal. 3rd ed. São Paulo: Artes Médicas; 2003. p. 327-340.

3. Diamanti-Kipioti A, Gusberti FA, Lang NP. Clinical and microbiological effects of fixed orthodontic appliances. $J$ Clin Periodontol. 1987;14(6):326-333.

4. Boyd RL, Leggott PJ, Quinn RS, et al. Periodontal implications of orthodontic treatment in adults with reduced or normal periodontal tissues versus those of adolescents. Am J Orthod Dentofacial Orthop. 1989;96(3):191-198.

5. Ong MA, Wang HL. Periodontic and orthodontic treatment in adults. Am J Orthod Dentofacial Orthop. 2002;122(4):420-428.

6. Ong MA, Wang HL, Smith FN. Interrelationship between periodontics and adult orthodontics. J Clin Periodontol. 1998;25(4):271-277. 
7. van Gastel J, Teughels W, Quirynen M, et al. Longitudinal changes in gingival crevicular fluid after placement of fixed orthodontic appliances. Am J Orthod Dentofacial Orthop. 2011;139(6):735-44.

8. Thornberg MJ, Riolo CS, Bayirli B, et al. Periodontal pathogen levels in adolescents before, during, and after fixed orthodontic appliance therapy. Am J Orthod Dentofacial Orthop. 2009;135(1):95-98.

9. Zachrisson S, Zachrisson BU. Gingival condition associated with orthodontic treatment. Angle Orthod. 1972;42(1):26-34.

10. Naranjo AA, Triviño ML, Jaramillo A, et al. Changes in the subgingiva microbiota and periodontal parameters before and 3 months after bracket placement. Am J Orthod Dentofacial Orthop. 2006;130(3):275e17-22.

11. van Gastel J, Quirynen M, Teughels W, et al. Influence of bracket design on microbial and periodontal parameters in vivo. J Clin Periodontol. 2007;34:423-431.

12. Lo Bue AM, Di Marco R, Milazzo I, et al. Microbiological and clinica periodontal effects of fixed orthodontic appliances in pediatric patients. New Microbiol. 2008;31(2):299-302.

13. Kloehn JS, Pfeifer JS. The effect of orthodontic treatment on the periodontium. Angle Orthod. 1974;44(2):127-134.

14. Trossello VK, Gianelly AA. Orthodontic treatment and periodontal status. J Periodontol. 1979;50(12):665-671.

15. Zachrisson BU, Alnaes L. Periodontal condition in orthodontically treated and untreated individuals I. Loss of attachment, gingival pocket depth and clinical crown height. Angle Orthod. 1973;43(4):402-411.

16. Zachrisson BU. Cause and prevention of injuries to teeth and supporting structures during orthodontic treatment. Am J Orthod. 1976;69(3):285300 .

17. Swennen GR. Three-dimensional cephalometry: spiral multi-slice vs cone-beam computed tomography. Am J Orthod Dentofacial Orthop. 2006;130(3):410-416.

18. Lopes PML. Aplicação de medidas cefalométricas em 3D-TC. Dental Press J Orthod. 2007;12(4):99-106. 2007.

19. Teles RP, Haffajee AD, Socransky SS. Microbiological goals of periodontal therapy. Periodontol. 2006;42:180-218.

20. Listgarten MA, Helldén L. Relative distribution of bacteria at clinically healthy and periodontally diseased sites in humans. J Clin Periodontol. 1978;5(2):115-132.

21. Loesche WJ. Chemotherapy of dental plaque infections. Oral Sci Rev. 1976;9:65-107.

22. Löe H, Anerud A, Boysen H, et al. The natural history of periodontal disease in man. The rate of periodontal destruction before 40 years of age. J Periodontol. 1978;49(12):607-620.

23. Löe H, Anerud A, Boysen H, et al. Natural history of periodontal disease in man. Rapid, moderate and no loss of attachment in Sri Lankan laborers 14 to 46years of age. J Clin Periodontol. 1986;13(5):431-445.

24. Petti S, Barbato E, Simonetti D'Arca A. Effect of orthodontic therapy with fixed and removable appliances on oral microbiota: a six-month longitudinal study. New Microbiol. 1997;20(1):55-62.

25. Perinetti G, Paolantonio M, Serra E, et al. Longitudinal monitoring of subgingival colonization by Actinobacillus actinomycetemcomitans, and crevicular alkaline phosphatase and aspartate aminotransferase activities around orthodontically treated teeth. J Clin Periodontol. 2004;31(1):60 67.

26. Sallum EJ, Nouer DF, Klein MI, et al. Clinical and microbiologic changes after removal of orthodontic appliances. Am J Orthod Dentofacial Orthop. 2004;126(3):363-366.
27. Speer C, Pelz K, Hopfenmuller W, et al. Investigation on the influencing of the Subgingival Microflora in chronic periodontitis. A study in adult patients during fixed appliance therapy. J Orofac Orthop. 2004;65(1):34 47.

28. Karkhanechi M, Chow D, Sipkin J, et al. Periodontal status of adult patients treated with fixed buccal appliances and removable aligners over one year of active orthodontic therapy. Angle Orthod. 2013;83(1):146151.

29. Torlakovic L, Paster BJ, Ogaard B, et al. Changes in the supragingival microbiota surrounding brackets of upper central incisors during orthodontic treatment. Acta Odontol Scand. 2013;71(6):1547-1554.

30. Ghijselings E, Coucke W, Verdonck A, et al. Long-term changes in microbiology and clinical periodontal variables after completion of fixed orthodontic appliances. J Orthod Craniofac Res. 2014;17(1):49-59.

31. Ireland AJ, Soro V, Sprague SV, et al. The effects of different orthodontic appliances upon microbial communities. Orthod Craniofac Res. 2014;17(2):115-123.

32. Yáñez-Vico RM, Iglesias-Linares A, Ballesta-Mudarra S, et al. Shortterm effect of removal of fixed orthodontic appliances on gingival health and subgingival microbiota: A prospective cohort study. Acta Odontol Scand. 2015;73(7):496-502.

33. Boyd RL, Baumrind S. Periodontal considerations in the use of bonds or bands on molars in adolescents and adults. Angle Orthod. 1992;62(2):117126.

34. Paolantonio M, Festa F, di Placido G, et al. Sitespecific subgingival colonization by Actinobacillus actinomycetemcomitans in orthodontic patients. Am J Orthod Dentofacial Orthop. 1999;115(4):423-428.

35. Anhoury P, Nathanson D, Hughes CV, et al. Microbial profile on metallic and ceramic bracket materials. Angle Orthod. 2002;72(4):338-343.

36. Gkantidis N, Christou P, Topouzelis N. The orthodontic interrelationdhip in integrated treatment challenges: a systematic review. J Oral Rehabil. 2010;37(5):37-390.

37. Rêgo RO, Oliveira CA, Santos-Pinto A, et al. Clinical and microbiological studies of children and adolescents receiving orthodontic treatment. Am J Dent. 2010;23(6):317-323.

38. Gong Y, Lu J, Ding X. Clinical, microbiologic, and immunologic factors of orthodontic treatment-induced gingival enlargement. Am J Orthod Dentofacial Orthop. 2011;140(1):58-64.

39. Reichert C, Hagner M, Jepsen S, et al. Interfaces between orthodontic and periodontal treatment: their current status. J Orofac Orthop. 2011;72(3):165-186.

40. Baka ZM, Basciftci FA, Arslan U. Effects of 2 bracket and ligation types on plaque retention: a quantitative microbiologic analysis with real-time polymerase chain reaction. Am J Orthod Dentofacial Orthop. 2013;144(2):260-267.

41. Artun J, Urbye KS. The effect of orthodontic treatment on periodontal bone support in patients with advanced loss of marginal periodontium. Am J Orthod Dentofacial Orthop. 1988;93(2):143-148.

42. Melsen B, Agerbaek N, Markenstam G. Intrusion of incisors in adul patients with marginal bone loss. Am J Orthod Dentofacial Orthop. 1989;96(3):232-241.

43. Cardaropoli D, Re S, Corrente G, et al. Intrusion of migrated incisors with infrabony defects in adult periodontal patients. Am J Orthod Dentofacial Orthop. 2001;120(6):671-675.

44. Melsen B, Agerbaek N, Eriksen J, et al. New attachment through periodontal treatment and orthodontic intrusion. Am J Orthod Dentofacial Orthop. 1988;94(2):104-116. 
45. Merrett SJ, Drage NA, Durning P. Cone beam computed tomography: a useful tool in orthodontic diagnosis and treatment planning. J Orthod. 2009;36(3):202-210.

46. Sherrard JF, Rossouw PE, Benson BW, et al. Accuracy and reliability of tooth and root lengths measured on cone-beam computed tomographs. Am J Orthod Dentofacial Orthop. 2010;137(4 Suppl):S100-108.

47. Kokich VG. Managing complex orthodontic problems: the use of implants for anchorage. Semin Orthod. 1996;2(2):153-160.

48. Huang LH, Shotwell JL, Wang HL. Dental implants for orthodontic anchorage. Am J Orthod Dentofacial Orthop. 2005;127(6):713-722.

49. Mengel R, Candir M, Shiratori K, et al. Digital volume tomography in the diagnosis of periodontal defects: an in vitro study on native pig and human mandibles. J Periodontol. 2005;76(5):665-673.

50. Ludlow JB, Ivanovic M. Comparative dosimetry of dental CBCT devices and 64slice CT for oral and maxillofacial radiology. Oral Surg Oral Med Oral Pathol Oral Radiol Endod. 2008;106(1):106-114.

51. Naito T, Hosokawa R, Yokota M. Three-dimensional alveolar bone morphology analysis using computed tomography. $J$ Periodontol. 1998;69(5):584-589.

52. Misch KA, Yi ES, Sarment DP. Accuracy of cone beam computed tomography for periodontal defect measurements. J Periodontol. 2006;77(7):1261-1266

53. Grimard BA, Hoidal MJ, Mills MP, et al. Comparison of clinical, periapical radiograph, and cone-beam volume tomography measurement techniques for assessing bone level changes following regenerative periodontal therapy. J Periodontol. 2009;80(1):48-55.

54. Nahás-Scocate AC, Scocate MC. A classification of alveolar bone tissue Quintessence Int. 2014;45(6):515-519.

55. Acar B, Kamburoglu K. Use of cone beam computed tomography in periodontology. World J Radiol. 2014;28;6(5):139-47.

56. Scarfe WC, Farman AG, Sukovic P. Clinical applications of conebeam computed tomography in dental practice. J Can Dent Assoc. 2006;72(1):75-80.

57. Garib DG, Rubens Raymundo Jr, Melissa VR, et al. Tomografia computadorizada de feixe cônico (cone beam): entendendo este novo método de diagnóstico por imagem com promissora aplicabilidade na Ortodontia. Rev Dental Press Ortod Ortop Fac. 2007;12(2):139-156.

58. Cattaneo PM, Treccani M, Carlsson K, et al. Transversal maxillary dento-alveolar changes in patients treated with active and passive self- ligating brackets: a randomized clinical trial using CBCT-scans and digital models. Orthod Craniofac Res. 2011;14(4):222-233.

59. Kapila S, Conley RS, Harrell WE Jr. The current status of cone beam computed tomography imaging in orthodontics. Dentomaxillofac Radiol. 2011;40(1):24-34.

60. Abdelkarim A., Myths and facts of cone beam computed tomography in orthodontics. J World Fed Orthod. 2012;1(1):e3-8.

61. Sun L, Zhang L, Shen G, et al. Accuracy of cone-beam computed tomography in detecting alveolar bone dehiscences and fenestrations. Am J Orthod Dentofacial Orthop. 2015;147(3):313-323.

62. Haney E, Gansky SA, Lee JS, Johnson E, et al. Comparative analysis of traditional radiographs and cone-beam computed tomography volumetric images in the diagnosis and treatment planning of maxillary impacted canines. Am J Orthod Dentofacial Orthop. 2010;137(5):590-597.

63. Lund H, Gröndahl K, Gröndahl HG. Cone beam computed tomography for assessment of root length and marginal bone level during orthodontic treatment. Angle Orthod. 2010;80(3):466-473.
64. Nahás-Scocate AC, de Siqueira Brandão A, Patel MP, et al. Bone tissue amount related to upper incisors inclination. Angle Orthod. 2014;84(2):279-285.

65. Grunheid T, Kolbeck Schieck JR, Pliska BT, et al. Dosimetry of a conebeam computed tomography machine compared with a digital x-ray machine in orthodontic imaging. Am $J$ Orthod Dentofacial Orthop. 2012;141(4):436-443.

66. Farman AG, Scarfe WC. Development of imaging selection criteria and procedures should precede cephalometric assessment with cone-beam computed tomography. Am J Orthod Dentofacial Orthop. 2006;130(2):257-65.

67. Silva MAG, Wolf U, Heinicke F, et al. Cone-Beam computed tomography for routine orthodontic treatment planning: a radiation dose evaluation. Am J Orthod Dentofac Orthop. 2008;133(5):640e1-e5.

68. Lorenzoni DC, Bolognese AM, Garib DG, et al. Conebeam computed tomography and radiographs in dentistry: aspects related to radiation dose. Int J Dent. 2012. p. 1-10.

69. Pauwels R, Beinsberger J, Collaert B, et al. Effective dose range for dental cone beam computed tomography scanners. Eur J Radiol. 2012;81(2):267-271

70. Harrell Jr WE, Stanford S, Bralower P. ADA initiates development of orthodontic binformatics standards. Am J Orthod Dentofacial Orthop. 2005;128(2):153-156.

71. Morais JF. Evaluation of the effects of the Damon System on the dental inclinations, dimensions of the arches and alveolar bone support by means of the conical beam computed tomography. Bauru: Thesis ( $\mathrm{PhD}$ in Orthodontics) University of São Paulo, 2012. 213 p.

72. Scarfe WC, Farman AG. What is cone-beam CT and how does it work? Dent Clin North Am. 2008;52(4):707-730.

73. Mozzo P, Procacci C, Tacconi A, et al. A new volumetric CT machine for dental imaging based on the conebeam technique: preliminary results. Eur Radiol. 1998;8(9):1558-1564.

74. Maki K, Inou N, Takanishi A, et al. Computer-assisted simulations in orthodontic diagnosis and the application of a new cone beam X-ray computed tomography. Orthod Craniofac Res. 2003;6 Suppl 1:95-101.

75. Kobayashi K, Shimoda S, Nakagawa Y, et al. Accuracy in measuremen of distance using limited conebeam computerized tomography. Int J Oral Maxillofac Implants. 2004;19(2):228-231.

76. Cevidanes LH, Bailey LJ, Tucker GR Jr, et al. Superimposition of 3D cone-beam CT models of orthognathic surgery patients. Dentomaxillofac Radiol. 2005;34(6):369-375.

77. Hilgers ML, Scarfe WC, Scheetz JP, et al. Accuracy of linear temporomandibular joint measurements with cone beam computed tomography and digital cephalometric radiography. Am J Orthod Dentofacial Orthop. 2005;128(6):803-811.

78. Marmulla R, Wörtche R, Mühling J, et al. Geometric accuracy of the NewTom 9000 Cone Beam CT. Dentomaxillofac Radiol. 2005;34(1):2831

79. Moshiri M, Scarfe WC, Hilgers ML, et al. Accuracy of linear measurements from imaging plate and lateral cephalometric images derived from cone-beam computed tomography. Am J Orthod Dentofacial Orthop. 2007;132(4):550-560.

80. Stratemann SA, Huang JC, Maki K, et al. Comparison of cone beam computed tomography imaging with physical measures. Dentomaxillofac Radiol. 2008;37(2):80-93.

81. Hashimoto K, Arai Y, Iwai K, et al. A comparison of a new limited cone beam computed tomography machine for dental use with a multidetector 
row helical CT machine. Oral Surg Oral Med Oral Pathol Oral Radiol Endod. 2003;95(3):371-377.

82. Holberg C, Steinhäuser S, Geis P, et al. Cone-beam computed tomography in orthodontics: benefits and limitations. J Orofac Orthop. 2005;66(6):434-444.

83. Walker L et al. Three-dimensional localization of maxillary canines with conebeam computed tomography. Am J Orthod Dentofacial Orthop. $2005 ; 128(4): 418-423$.

84. Ericson S, Kurol J. Resorption of incisors after ectopic eruption of maxillary canines: a CT study. Angle Orthod. 2000;70(6):415-423.

85. Fuhrmann RA, Bücker A, Diedrich PR. Assessment of alveolar bone loss with high resolution computed tomography. $J$ Periodontal Res. 1995;30(4):258-263.

86. Fuhrmann R. Three-dimensional interpretation of periodontal lesions and remodeling during orthodontic treatment. Part III. J Orofac Orthop. 1996;57(4):224-237.

87. Fuhrmann RA, Bücker A, Diedrich P. Radiological assessment of artificial bone defects in the floor of the maxillary sinus. Dentomaxillofac Radiol. 1997;26(2):112-116.

88. Fuhrmann RA. Three-Dimensional evaluation of periodontal remodeling during orthodontic treatment. Sem Orthod. 2002;8(1):21-28.

89. Sarikaya S, Haydar B, Ciğer S, et al. Changes in alveolar bone thickness due to retraction of anterior teeth. Am J Orthod Dentofacial Orthop. 2002;122(1):15-26.

90. Garib DG, Henriques JF, Janson G, et al. Periodontal effects of rapid maxillary expansion with toothtissueborne and tooth-borne expanders: a computed tomography evaluation. Am J Orthod Dentofacial Orthop. 2006;129(6):749-758.

91. Podesser B. Quantitation of transverse maxillary dimensions using computed tomography: a methodological and reproducibility study. Eur J Orthod. 2004;26(2):209-215.

92. Garib DG, Henriques JF, Janson G, et al. Rapid maxillary expansion-tooth tissue-borne versus toothborne expanders: a computed tomography evaluation of dentoskeletal effects. Angle Orthod. 2005;75(4):548-557.

93. Gunduz E, Rodríguez-Torres C, Gahleitner A, et al. Bone regeneration by bodily tooth movement: dental computed tomography examination of a patient. Am J Orthod Dentofacial Orthop. 2004;125(1):100-106.

94. Arctander K. Computed tomography of alveolar bone grafts 20years after repair ofunilateralcleftlipandpalate. Scand J Plast Reconstr Surg Hand Surg. 2005;39(1):11-14.

95. Feichtinger M, Mossböck R, Kärcher H. Evaluation of bone volume following bone grafting in patients with unilateral clefts of lip, alveolus and palate using a CT-guided threedimensional navigation system. J Craniomaxillofac Surg. 2006;34(3):144-149.

96. Kim KR, Kim S, Baek SH. Change in grafted secondary alveolar bone in patients with UCLP and UCLA. A three-dimensional computed tomography study. Angle Orthod. 2008;78(4):631-640.

97. Gahleitner A, Podesser B, Schick S, et al. Dental CT and orthodontic implants: imaging technique and assessment of available bone volume in the hard palate. Eur J Radiol. 2004;51(3):257-262.

98. Lim JE. Lim WH, Chun YS. Quantitative evaluation of cortical bone thickness and root proximity at maxillary interradicular sites for orthodontic mini-implant placement. Clin Anat. 2008;21(6):486-491.
99. Chun YS, Lim WH. Bone density at interradicular sites: implications for orthodontic miniimplant placement. Orthod Craniofac Res. 2009;12(1):25-32.

100. Monnerat C, Restle L, Mucha JN. Tomographic mapping of mandibular interradicular spaces for placement of orthodontic mini-implants. Am J Orthod Dentofacial Orthop. 2009;135(4):428e1-9.

101. Chidiac JJ, Shofer FS, Al-Kutoub A, et al. Comparison of CT scanograms and cephalometric radiographs in craniofacial imaging. Orthod Craniofac Res. 2002;5(2):104-113.

102. Cevidanes LH, Bailey LJ, Tucker SF, et al. Three-dimensional cone-beam computed tomography for assessment of mandibular changes after orthognathic surgery. Am J Orthod Dentofacial Orthop. 2007;131(1):44-50.

103. Kumar V, Ludlow J, Soares Cevidanes LH, et al. In vivo comparison of conventional and cone beam CT synthesized cephalograms. Angle Orthod. 2008;78(5):873-879.

104. Steiner GG, Pearson JK, Ainamo J. Changes of the marginal periodontium as a result of labial tooth movement in monkeys. $J$ Periodontol. 1981;52(6):314-320

105. Engelking G, Zachrisson BU. Effects of incisor repositioning on monkey periodontium after expansion through the cortical plate. Am J Orthod. 1982;82(1):23-32.

106. Thilander B, Nyman S, Karring T, et al. Bone regeneration in alveolar bone dehiscences related to orthodontic tooth movements. Eur J Orthod. 1983;5(2):105-114

107. Wennstrom JL, Lindhe J, Sinclair F, et al. Some periodontal tissue reactions to orthodontic tooth movement in monkeys. J Clin Periodontol. 1987;14(3):121-129.

108. Wehrbein H. Periodontal conditions after facial root tipping and palatal root torque of incisors. Am J Orthod Dentofacial Orthop. 1994;106(5):455-462.

109. Wehrbein H, Fuhrmann RA, Diedrich PR. Human histologic tissue response after long-term orthodontic tooth movement. Am J Orthod Dentofacial Orthop. 1995;107(4):360-371.

110. Wehrbein H, Bauer W, Diedrich P. Mandibular incisors, alveolar bone, and symphysis after orthodontic treatment. A retrospective study. Am J Orthod Dentofacial Orthop. 1996;110(3):239-246.

111. Mulie RTH. The limitations of tooth movement within the synphysis studied with laminagraphy and standardized occlusal fims. J Clin Orthod. 1976;10(12):882-899.

112. Ten Hoeve AM. The effect of antero-posterior incisor repositioning on the palatal cortex as studied with laminagraphy. J Clin Orthod. 1976;10(11):804-822

113. Artun J, Krogstad O. Periodontal status of mandibular incisors following excessive Pro clination. A study in adults with surgically treated mandibular prognathism. Am J Orthod Dentofacial Orthop. 1987;91(3):225-232.

114. Andlin-Sobocki A, Bondin L. Dimensional alterations of the gingiva related to changes of facial/lingual tooth position in permanent anterior teeth of children. A 2-year longitudinal study. J clin Periodont. 1993;20(3):219-224.

115. Andlin-Sobocki A, Persson M. The association between spontaneous reversal of gingival recession in mandibular incisors and dentofacial changes in children. A 3-year longitudinal study. Europ J Orthodont. 1994;16(3):229-239. 
116. Artun J, Grobety D. Periodontal status of mandibular incisors after pronounced orthodontic advancement during adolescence: a follow-up evaluation. Am J Orthod Dentofacial Orthop. 2001;119(1):2-10.

117. Kim Y, et al. Alveolar bone loss around incisors in surgical skeletal Class III patients. Angle Orthod. 2009;79(4):676-682.
118. Rungcharassaeng K, Caruso JM, Kan JY, et al. Factors affecting buccal bone changes of maxillary posterior teeth after rapid maxillary expansion. Am J Orthod Dentofacial Orthop. 2007;132(4):428e1-e8. 